Vietnam Journal of Mechanics, NCST of Vietnam Vol. 23, 2001, No4 (216-223)

\title{
RELIABILITY - SAFETY SET OF STRUCTURES
}

\author{
Le Xuan Huynh, Do Van Binh \\ University of Civil Engineering
}

\begin{abstract}
Based on the results of A. D. Rzanitsin and V. D. Raizer in the references of [1] and [2], this paper gives other definitions of the confidence level of subjected loads $\beta_{S}$ and the confidence level of the strength of materials $\beta_{R}$, then studies the relationship between the load factor $k$, the material factor $m$ and the safety factor $n$ in the traditional models with the factors of $\beta_{S}, \beta_{R}$ and $\beta$ in the random models in the structural design. The research results show that physical meaning of two factors of $\beta_{S}, \beta_{R}$ is the same as the factors of $k$ and $m$, however it gives more clearly assessements on effects of the over load state and the material inhomogeneous state of the safety working state of the structures. Since the reliability - safety set is also determined from the research results. Some numerical examples are carried out to show the relationship between these above factors.
\end{abstract}

\section{Introduction}

The structural analysis by the ordinary models has been based on the safety factor $n>1$, which is combined by many factors such as loads, materials and working states of the structures. However, two main factors are accounted in determining the safety factor $n$, that are the factor $k>1$ which is called as the overload factor and the factor $m<1$ which is called as the quality factor of the structures.

When the structures are analyzed by the random models, the reliability index $\beta$ is used to determine safety probability of the structures. Therefore, the reliability index $\beta$ must relate to the working state and the strength of materials of the structures. So the safety factor $n$ must relate to the reliability index $\beta$.

Based on the research results of A. R. Rzanitsin [1] and V. D. Raiser [2], in this paper the confidence level of subjected loads $\beta_{S}$ and the confidence level of strength of materials $\beta_{R}$ are provided, then the relations between the factors $k, m$ and $n$ in the ordinary models with the factors $\beta_{S}, \beta_{R}$ and $\beta$ in the random models are considered. It is clearly that the physical meaning of the factors $\beta_{S}$ and $\beta_{R}$ is similar to the factors $k$ and $m$, however this research provides more clearly the assessments on the effects of the overload state and the inhomogeneous state of the materials on the safety working state of the structures.

Based on the research results the relations between the safety $n$ and the reliability index $\beta$ are also provided to determine the reliability - safety set of the structures. The obtained results can be used to compare the reliability - safety factor with the usual safety factor in form of the formulations and charts. 


\section{Summary of the analysis of the structures by the random models}

Generally, in the analysis of the structures the following function is used:

$$
M=F\left(x_{1}, x_{2}, \ldots, x_{n}\right)
$$

where $M$ is not over a certain value $M_{0}$

$$
M<M_{0} .
$$

In the equation (2.1) $x_{1}, x_{2}, \ldots, x_{n}$ are the random variables.

It can be say that the value of $M$ includes two main elements: a calculated carrying capacity $R$ and a corresponding load effects $S$. The normal working state of the structures can be shown:

$$
M=R-S>0 .
$$

For example, in the analysis of the strength of the structures, $R$ is the design strength of the structural member and $S$ is the design stress in the structural member. In fact, $R$ and $S$ are the random variables, therefore $M$ must be a random value.

In the analysis of the structures by the random models, $M$ is seen as the normal distribution shown in Fig. 1.

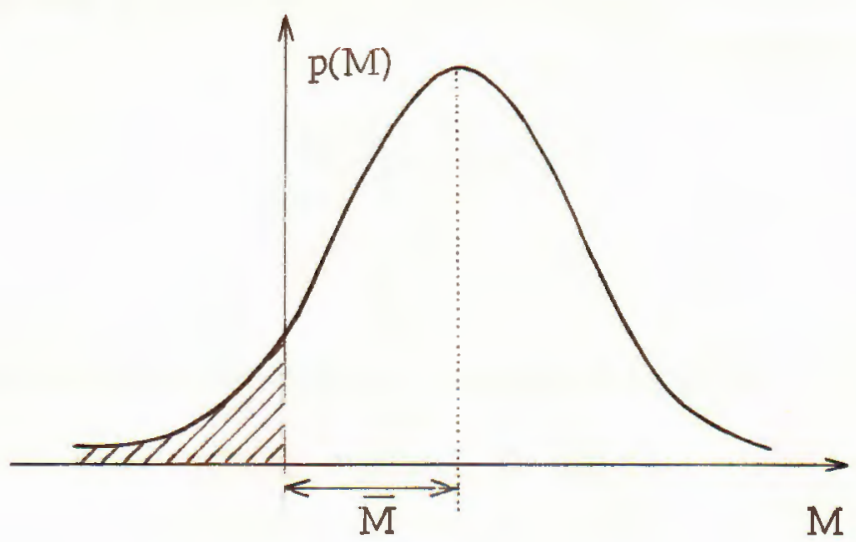

Fig. 1

Safety level of the structures is assessed by the probability of $P(M \geq 0)$ which is corresponding to the area limited by the curve and two positive axes. The area with italic line is corresponding to the failure probability of the structure.

For a simple purpose, the values of $R$ and $S$ can be seen the statistic independent which have mean values of $\bar{R}$ and $\bar{S}$ respectively and standard deviations of $\sigma_{R}$ and $\sigma_{S}$ respectively. Therefore, the mean value of $\bar{M}$ and standard deviation of $\sigma_{M}$ are

$$
\bar{M}=\bar{R}-\bar{S}, \quad \sigma_{M}=\left(\sigma_{R}^{2}+\sigma_{S}^{2}\right)^{1 / 2} .
$$


In the analysis of the structures by the random models A. R. Rzanitsin [1] and some other authors [3] used the concept of "the reliability character" or the reliability index $\beta$ such as

$$
\beta=\frac{\bar{M}}{\sigma_{M}}=\frac{\bar{R}-\bar{S}}{\left(\sigma_{R}^{2}+\sigma_{S}^{2}\right)^{1 / 2}} .
$$

The safety probability is determined from the reliability index $\beta$ :

$$
P(M>0)=\frac{1}{2}+\Phi(\beta)
$$

where

$$
\Phi(\beta)=\frac{1}{\sqrt{2 \pi}} \int_{0}^{\beta} \exp \left(-\frac{X^{2}}{2}\right) d X .
$$

Moreover, the safety state of the structures can be shown:

$$
n=\frac{\bar{R}}{\bar{S}}>1
$$

A. R. Rzanitsin [1] gave the formulas of the overload factor $k$ and the inhomogeneous material factor $m$, respectively:

$$
\begin{aligned}
& k=\frac{\left(\bar{S}+\beta \sigma_{S}\right)}{\bar{S}} \\
& m=\frac{\left(\bar{R}-\beta \sigma_{R}\right)}{\bar{R}}
\end{aligned}
$$

V. D. Raizer [2] gave the certain level for $R$ and $S$ with the following definitions:

$$
\begin{gathered}
P\left(R>R_{t t}\right)=P_{R}=\Phi\left(\beta_{R}^{*}\right) \\
P\left(S<S_{t t}\right)=P_{S}=\Phi\left(\beta_{S}^{*}\right)
\end{gathered}
$$

where $R_{t t}$ and $S_{t t}$ are the design values of $R$ and $S$, respectively and $\Phi\left(\beta_{S}^{*}\right)$ is calculated as same as the equation (2.7).

From (2.11) and (2.12) obtained

$$
\beta_{B}^{*}=\Phi^{-1}\left(P_{B}\right) \text { and } \beta_{S}^{*}=\Phi^{-1}\left(P_{S}\right) .
$$

Therefore, in order to use V. D. Raizer's formula the values of $P_{R}$ and $P_{S}$ have to be known in advance, then use the probability integration tables to determine of $\beta_{R}^{*}$ and $\beta_{S}^{*}$. However, in fact the reliability index $\beta_{0}$ or $P\left(\beta_{0}\right)$ can be taken from the codes, but the values of $P_{R}$ and $P_{S}$ have been not in the codes yet. 
3. Confidence levels on the strength of materials and the subjected loads

\subsection{Two definitions}

This research gives more clearly two definitions on the confidence level of the strength materials and the confidence level of the subjected loads, which have the measure meaning than the reliability index $\beta$ of $\mathrm{A}$. D. Rzanitsin

a. The confidence level of the strength materials is defined

$$
\beta_{R}=\frac{\bar{R}}{\sigma_{R}}
$$

b. The confidence level of the subjective loads is defined

$$
\beta_{S}=\frac{\bar{S}}{\sigma_{S}} .
$$

From these definitions, on the forms of two factors $\beta_{R}$ and $\beta_{S}$ are the same as the A. D. Rzanitsin's definition on the $\beta$ factor. Therefore, the meaning of $\beta_{R}$ is a value without unit and it gives the mean value $\bar{R}$ of the structural member that is equivalent to $\beta_{R}$ times of the its standard deviation $\sigma_{R}$. The meaning of $\beta_{S}$ is similarly.

3.2. The relations of the levels of $\beta_{k}$ and $\beta_{S}$ with the factors of $n, k, m$ and $\beta$.

3.2.1. The relations between $\beta_{R}$ and $\beta_{S}$ with $n$ and $\beta$

From the equations (2.5) and (2.8) we obtain:

$$
\beta=\frac{(n-1)}{\left[\left(\sigma_{R}^{2}+\sigma_{S}^{2}\right) / \bar{S}^{2}\right]^{1 / 2}}
$$

then taking into account the equations (3.1) and (3.2) it becomes

$$
\begin{aligned}
& \beta=\frac{(n-1)}{\left[\beta_{S}^{-2}+\beta_{R}^{-2} n^{2}\right]^{1 / 2}} \\
& n=\frac{\left[1+\beta\left(\beta_{R}^{-2}+\beta_{S}^{-2}-\beta_{R}^{-2} \beta_{S}^{-2}\right)^{1 / 2}\right]}{\left(1-\beta^{2} \beta_{R}^{-2}\right)}
\end{aligned}
$$

3.2.2. The relations between $\beta_{R}$ and $\beta_{S}$ with $k, m$ and $\beta$

From the equations (2.9) and (2.10) and the equations (3.1) and (3.2) it gives:

$$
\begin{aligned}
k & =1+\beta \beta_{S}^{-1} \\
m & =1-\beta \beta_{R}^{-1}
\end{aligned}
$$


or

$$
\begin{aligned}
& \beta_{S}=\frac{\beta}{(k-1)} \\
& \beta_{R}=\frac{\beta}{(1-m)}
\end{aligned}
$$

From the equation (3.7) and (3.8) the final result is obtained:

$$
\frac{\beta_{R}}{\beta_{S}}=\frac{(k-1)}{(1-m)}
$$

4. The numerical examples of the relations between the confidence levels of $\beta_{R}$ and $\beta_{S}$ with the factors of $k, m$ and $\beta$.

The following examples show the relations between the factors of $k, m$ and $n$ in the structural analysis with the indexes of $\beta_{R}$ and $\beta_{S}$ as defined in the equation (3.1) and (3.2) with the reliability index $\beta$ used in the usual structural analysis.

\begin{tabular}{|c|c|c|c|c|c|c|}
\hline$\beta$ & $P(M>0)$ & $\beta_{S}$ & $\beta_{R}$ & $\sigma_{S} / \bar{S}$ & $\sigma_{R} / \bar{R}$ & $n$ \\
\hline (1) & $(2)$ & (3) & (4) & (5) & $(6)$ & $(7)$ \\
\hline 1.5 & 0.9619 & 5.0 & 15 & $20 \%$ & $6.7 \%$ & 1.328 \\
\hline 2.0 & 0.9725 & 6.66 & 20 & $15 \%$ & $5.0 \%$ & 1.328 \\
\hline 2.5 & 0.9937 & 8.33 & 25 & $12 \%$ & $4.0 \%$ & 1.328 \\
\hline 3.0 & 0.99865 & 10 & 30 & $10 \%$ & $3.3 \%$ & 1.328 \\
\hline 3.5 & 0.99977 & 11.66 & 35 & $8.75 \%$ & $2.85 \%$ & 1.328 \\
\hline 4.0 & 0.99996 & 13.33 & 40 & $7.5 \%$ & $2.5 \%$ & 1.328 \\
\hline
\end{tabular}

4.1. If $k=1.3$ and $m=0.9$

Table 1

\begin{tabular}{|c|c|c|c|c|c|c|}
\hline$\beta$ & $P(M>0)$ & $\beta_{S}$ & $\beta_{R}$ & $\sigma_{S} / \bar{S}$ & $\sigma_{R} / \bar{R}$ & $n$ \\
\hline (1) & (2) & (3) & (4) & (5) & (6) & (7) \\
\hline 1.5 & 0.9619 & 3 & 7.5 & $33 \%$ & $13 \%$ & 1.592 \\
\hline 2.0 & 0.9725 & 4 & 10 & $25 \%$ & $10 \%$ & 1.592 \\
\hline 2.5 & 0.9937 & 5 & 12.5 & $20 \%$ & $8 \%$ & 1.592 \\
\hline 3.0 & 0.96865 & 6 & 15 & $16.6 \%$ & $6.7 \%$ & 1.592 \\
\hline 3.5 & 0.99977 & 7 & 17.5 & $14.2 \%$ & $5.7 \%$ & 1.592 \\
\hline 4.0 & 0.99996 & 8 & 20 & $12.5 \%$ & $5.9 \%$ & 1.592 \\
\hline
\end{tabular}

4.2. If $k=1.5$ and $m=0.8$

Table 2 


\section{Reliability-safety set}

The equation (2.8) can be shown by a chart, which shows the failure set and the safety set as in Fig. 2. point $N\left(\bar{R}_{N}, \bar{S}_{N}\right)$ is in the safety set and point $M\left(\bar{R}_{M}, \bar{S}_{M}\right)$ is in the failure set.

From equation (2.5) one can obtain certain condition for the reliability:

$$
\beta=\frac{\bar{R}-\bar{S}}{\left(\sigma_{R}^{2}+\sigma_{S}^{2}\right)^{1 / 2}}>\beta_{0}
$$

where $\beta_{0}$ is the given reliability index for the structure.

The equation (5.1) can be written

$$
\frac{\bar{R}}{\bar{S}+\Delta\left(\beta_{0}, \sigma_{R}, \sigma_{S}\right)}>1
$$

where $\Delta\left(\beta_{0}, \sigma_{R}, \sigma_{S}\right)=\beta_{0}\left[\sigma_{R}^{2}+\sigma_{S}^{2}\right]^{1 / 2}$, note to the equation (3.1) and (3.2) the equation (5.2), it becomes

$$
n^{*}=n-\beta_{0}\left[\beta_{S}^{-2}+\beta_{R}^{2} n^{2}\right]^{1 / 2}>1
$$

The inequality (5.2) is the reliability - safety condition of the structures. The figure 3 shows the reliability - safety set and the unreliability-safety set. If the mean value of the design strength $\bar{R}_{d}$ of the structures is given, so the mean value of the design load $\bar{S}_{d}$ can be determined with the reliability $P=\frac{1}{2}+\Phi\left(\beta_{0}\right)$.

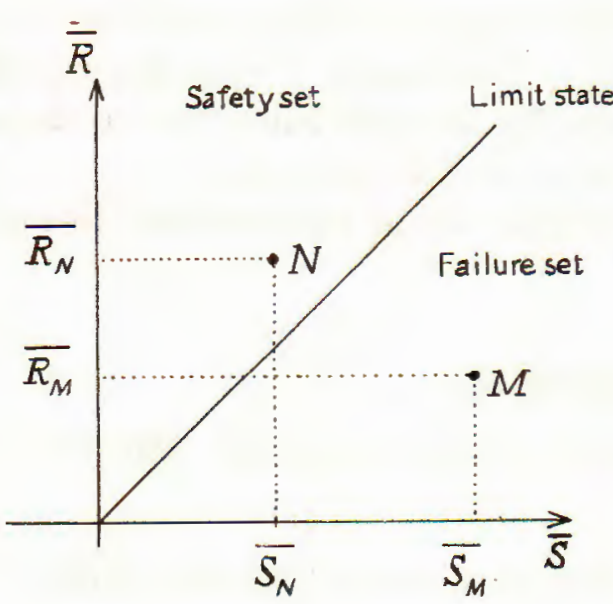

Fig. 2

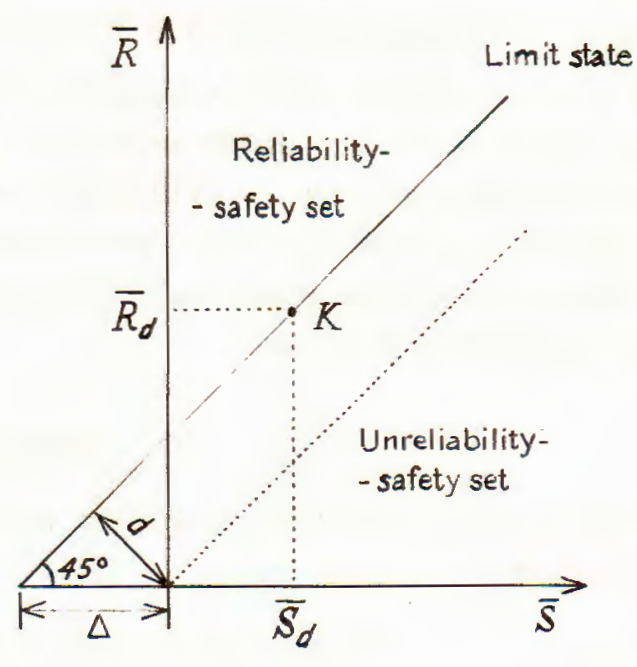

Fig. 3 


\section{Assessments and conclusions}

There are some assessments and conclusions drawn from the research results:

6.1. The same ratio of $k / m$ gives one the value of $n$, but the same ratio of $\beta_{S} / \beta_{R}$ gives the many different reliability probabilities $P(M>0)$. The reliability probabilities depend on $\beta_{S}$ and $\beta_{R}$.

6.2. The data in the columns (2), (5) and (6) of the Tables 1 and 2 give the effects of the standard deviations of $\sigma_{S}$ and $\sigma_{R}$ over their mean values $\bar{S}$ and $\bar{R}$ to the reliability P. For example, with $k=1.3$ and $m=0.9$ if the standard deviation of the subjected loads is less than of $7 \%$ compared to the value of the subjected loads and the standard deviation of the material strength is less than $20 \%$ of the maximum strength or can say that if the confidence level of the strength materials $\beta_{R}=40$ and the confidence level of subjected loads $\beta_{S}=13.5$, the structure is working in the nearly safe absolutely state $(99.996 \%)$.

6.3. If the safety factor is high, it does not mean that leads to the high reliability. However, if the reliability index is high, it must lead to the high reliability. These are different between the structural analysis based on the original models and the random models.

6.4. The definition of $\beta_{S}$ and $\beta_{R}$ in the equations (3.1) and (3.2) give the more clearly assessements of the effects of the standard deviations of two random values $R$ and $S$ to the structural reliability. The reliability index $\beta$ and two factors $\beta_{S}$ and $\beta_{R}$ make a set of three indexes with the clear physical meaning when analysing structures by the random models.

6.5. From the equantion (5.3), the new limit state (Fig. 3) is far from the old limit state (Fig. 2) on a distance up of $d=\frac{1}{2} \beta_{0} \sqrt{2\left(\sigma_{S}^{2}+\sigma_{R}^{2}\right)}$. With the given $\beta_{0}$, the standard deviations of $R$ and $S$ increase, so the distance $d$ increases too.

6.6. The reliability-safety condition in the equation (5.3) is more closed than the usual safety condition in the equation (2.8). The fasctor $n^{*}$ does not depend on $\bar{R}$ and $\bar{S}$ but depends on the reliability index $\beta_{0}$, the confidence level of the strength of materials $\beta_{R}$ and the confidence level of subjected loads $\beta_{S}$.

This research has been supported by a grant of the Fundamental Research Program in Natural Sciences.

\section{REFERENCES}

1. Rzanitsin A. R. The reliability method of the structures. Moscow, 1992 (in Russian).

2. Raizer V. D. Theory of reliability in structural design. Moscow, 1998.

3. Phan Van Khoi. Fatigue life time of offshore steel structures. Science and Technics Publishing House, Hanoi, 1997 (in Vienamese). 
4. Ditlevsen O.. Madsen H. O. Structural reliability methods. John Wiley \& Sons, England, 1996.

5. Korn A., Korn M. Mathematical Hanbook, McHill Book Company, 1968.

6. Le Xuan Huynh, Do Van Binh. Over load factor and material homogeneous factor in analysis of structures with random models. Proceedings of Structural Engineering Conference, Hanoi, 12-2000 (in Vietnamese).

Received July 2, 2001

\section{MIÊN AN TOÀN - TIN CÂYY CƯA KẾT CẤU}

Tiếp tục các nghiên cứu của $\mathrm{A}$. D. Ranhixưn và $\mathrm{V}$. D. Raizer trong các tài liệu tham khảo [1] và [2], trong bài này các tác giả đưa ra các định nghĩa về mức đảm bảo của tải trọng qua hệ số $\beta_{S}$ và mức đảm bảo dộ bền của vật liệu qua hệ số $\beta_{R}$. Khảo sát mối quan hệ giữa các hệ số vượt tải $k$, hệ số đồng nhất vật liệu $m$ và hệ số an toàn $n$ được sư dụng trong tính toán theo mô hình tiền định truyền thống với các hệ số $\beta_{S}, \beta_{R}$ và chì số độ tin cậy $\beta$ trong việc tính toán kết cấu theo mô hình ngâxu nhiên. Kết quả nghiên cứu qua các ví dụ bằng số cho thấy về mặt ý nghĩa vật lý các hệ số $\beta_{S}$ và $\beta_{R}$ tương tự như hệ số $k$ và $m$, nhưng cho phép đánh giá rõ ràng hơn về mức độ ánh hưởng của trạng thái vượt tải và sự phân tán của cường độ vật liệu đến trạng thái làm việc an toàn của kết cấu.

Trên cơ sở đó thiết lập mối quan hệ giữa hệ số an toàn $n$ và chî số độ tin cậy $\beta$ để xác định được miền an toàn - tin cậy khi tính toán công trình. Kết quá cho thấy miền an toàn biểu diễn qua hệ số an toàn $n$ là trường hợp riêng của miền an toàn - tin cậy biểu diễn qua hệ số $n^{*}$ tìm được trong bài này. 